\title{
Chronic bronchitis in textile workers
}

\author{
R McL Niven, A M Fletcher, C A C Pickering, D Fishwick, C J Warburton, \\ J C G Simpson, H Francis, L A Oldham
}

\begin{abstract}
Background - Exposure to cotton is known to produce a specific occupational disease known as byssinosis. A large population of textile workers was investigated to determine whether such exposure was also associated with chronic bronchitis once other possible aetiological factors had been accounted for.

Methods - A total of 2991 workers were investigated for the presence of symptoms compatible with chronic bronchitis. An MRC adapted respiratory questionnaire and MRC definition of chronic bronchitis were used for diagnostic labelling. Current and lifetime exposure to dust was estimated by personal and work area sampling, and the use of records of retrospective dust levels previously measured over the preceding 10 years. Airborne endotoxin exposure was measured using a quantitative turbidometric assay. Lung function tests were performed to measure forced expiratory volume in one second $\left(F E V_{1}\right)$ and forced vital capacity (FVC). A control group of workers exposed to manmade fibre textiles was identified. The comparative prevalence of chronic bronchitis in the two populations was assessed, allowing for sex, age, smoking habit, and ethnic origin. Two case referent studies were also performed; cases of chronic bronchitis were separately matched with controls from the cotton and control populations to determine the effect of the symptomatic state on lung function.
\end{abstract}

Results - After controlling for smoking (pack years), workers in a cotton environment were significantly more likely to suffer from chronic bronchitis and this was most marked in workers over 45 years of age (odds ratio 2.51 (CI 1.3 to 4.9); $p<0.01)$. Regression analysis of all possible influencing parameters showed that cumulative exposure to cotton dust was significantly associated with chronic bronchitis after the effects of age, sex, smoking, and ethnic group were accounted for $(p<0.0005)$. In the intra-cotton population case control study a diagnosis of chronic bronchitis was associated with a small decrement in lung function compared with controls: percentage predicted $\mathrm{FEV}_{1}$ in cases $81.4 \%$ (95\% CI 78.3 to 84.6$)$, controls $86.7 \%$ (84.9 to 88.5); FVC in cases $89.9 \%$ (95\% CI 87.0 to 92.9$)$, controls $94.6 \%$ (92.8 to 96.4). After controlling for cumulative past exposure and pack years of smoking the effect of the diagnostic state remained significant for both $\mathrm{FEV}_{1}(\mathrm{p}<0.01)$ and FVC $(\mathbf{p}<0.05)$.

Conclusions - Chronic bronchitis is more prevalent in cotton workers than in those working with man-made fibre and exposure is additive to the effect of smoking. The diagnosis of chronic bronchitis is associated with a small but significant decrement in lung function.

(Thorax 1997;52:22-27)

Keywords: cotton, man-made fibre, chronic bronchitis, smoking, lung function.

Chronic bronchitis is a disease of the respiratory system related to cigarette smoking. It is characterised by the presence of a cough with sputum production which is chronic and persistent. It has been described as such and can be investigated using questionnaire techniques in epidemiological studies. ${ }^{1}$

It has recently been accepted that chronic bronchitis may occur more commonly in some occupational groups, notably coal mining. ${ }^{2}$ There is also some evidence to suggest that there may be an excess of disease in foundry workers ${ }^{3}$ and steel workers. ${ }^{4}$ The study of these working populations has been made more difficult because of the confounding effect of smoking which remains clearly the most important aetiological factor. In the occupational groups where chronic bronchitis may occur as a result of industrial exposure to dust, smoking is prevalent among the work force and identifying sufficient numbers of workers who are lifelong non-smokers is difficult. Until smoking is adequately accounted for it is impossible to ascribe aetiological roles to occupational factors in the occurrence of bronchitis.

We have studied nearly 3000 workers on their first entry into a five year longitudinal study of the Lancashire textile industry. The prevalence of bronchitis has been investigated in cotton workers and compared with a control group of man-made fibre workers. The study methods and analysis were aimed at determining whether chronic bronchitis was more common in cotton workers than in man-made fibre workers, having accounted for the confounding effects of age, sex, ethnic origin, and smoking habits, and which occupational factors significantly affected the prevalence of chronic bronchitis. In addition, the effect of the severity of symptoms on lung function was investigated to determine whether chronic bronchitis, determined by a questionnaire, was associated with a significant decline in lung function.

Methods

POPULATION

An initial group of eight cotton and two manmade fibre textile mills were included in the 
planned longitudinal study. Due to a major recession within the industry, a number of cotton mills have closed during the course of the study. Whenever a mill closed it was replaced with another one. While this has hampered the longitudinal element of the original study, it has increased the population available for cross sectional investigation with 16 mills being included in the current study.

Every worker within each mill was invited to participate and received an introductory and explanatory letter.

QUESTIONNAIRE

The questionnaire used is a specifically adapted MRC respiratory questionnaire which includes the original chronic bronchitis questions ${ }^{1}$ but also establishes the diagnosis of byssinosis, the specific respiratory disease of cotton workers. A case of chronic bronchitis is diagnosed by the presence of a productive cough which persists for at least three months of the year and has been present for at least two consecutive years. Individuals gave full smoking histories, including types of smoking material, years smoked, and amount smoked per year. No measures were taken to support claimed smoking habits in view of the size of the population under investigation.

The interview was performed by one of three trained interviewers and the data were stored directly onto lap top portable computers.

LUNG FUNCTION

Each operative who took part in the questionnaire study was invited to perform a forced vital capacity procedure. One Vitalograph Series S dry wedge spirometer was used throughout the study and was calibrated by a trained technician prior to each mill visit. The best of three forced vital capacity manoeuvres was used as the recorded value. A minimum of three values with less than 5\% variability was required for an acceptable response. ${ }^{5}$ If the technique remained unacceptable it was repeated with the use of a nose clip. The temperature, as measured with a dry bulb thermometer, was recorded at the time of the procedure and the results corrected to BTPS values. Each individual result was compared against predicted values using the European summary equations. ${ }^{6}$ For Asian operatives the predicted lung function was calculated by using a $15 \%$ reduction from the predicted value for a white Caucasian subject. ${ }^{7}$

ASSESSMENT OF EXPOSURE

Over 52 different specific occupations were identified in the textile spinning environment. These were allocated to one of 19 occupational groups, which included occupations with similar dust exposure on the basis of work room, type of work performed and proximity to machinery. These groups were used to attribute dust exposures to individuals in specific occupations and work areas. Dust exposure levels were measured by both work area and personal sampling techniques for each group which was represented in each mill. Each operative was then ascribed a current dust exposure dependent on the work area in which he or she worked (work area) or by the occupational group (personal).

\section{WORK AREA SAMPLING}

The methodology used for work area sampling was as laid down by the Health and Safety Executive in the EH25 guidelines. ${ }^{8}$ This was also the method used by the mills in the hygiene analysis they performed to establish dust exposure over the previous 10 years.

Each process was studied on a yearly basis within four weeks of the questionnaire study. Each mill was divided into its different processes and each machine group was sampled in at least two different areas.

The mean of measured values for any specific area was used for all operatives who worked in that particular process of the mill. A predetermined protocol was produced to standardise the ascribing of occupational groups involving work across more than one geographical area within the mill.

\section{PERSONAL SAMPLING}

For personal sampling there is as yet no recommended method or standard for cotton dust exposure. For the duration of the study the Institute of Occupational Medicine sampling head was used to measure total dust exposure with $21 /$ min Casella sampling pumps attached to a harness with the head positioned close to the left clavicle. The samplers were worn for most of the working shift.

A standard protocol for estimating the exposure in any groups that did not have representative sampling was devised to allow ascribing of dust exposure to each operative in every mill.

\section{EXPOSURE TO ENDOTOXIN}

The exposure to airborne endotoxin for each occupational group was measured from the personal sampling filters using a quantitative assay. A LAL 5000 turbidometric analyser was used to determine the concentrations of endotoxin after a simple water extraction. ${ }^{9}$ Each individual occupational group was accredited with one of five grades of exposure based on a $\log$ value of the measured endotoxin exposure. Each grade was associated with a $\log 10$ increase in measured exposure over the previous group.

RETROSPECTIVE EXPOSURE TO DUST

Each mill visited was requested to produce dust levels measured by the work area technique for the previous eight years where possible. For most of the mills these data were reliable as a full time experienced hygienist had been performing regular dust sampling exercises using the protocol laid down by the Health and Safety Executive guidelines. Dust exposure for each 
work area was calculated yearly from 1981 to 1988. Our own data were available from 1989 onwards.

No reliable data were available for the years preceding 1981 and it is difficult to assess what the dust exposures were prior to this. Anecdotal reports would suggest declining dust levels in the preceding 20 years, while the data since 1981 show no specific declining trend and, if anything, an increase in dust levels. ${ }^{10}$ For the purpose of retrospective dust accreditation it was assumed that dust levels before 1981 were static. This may be inaccurate but an alternative prediction could not be supported from available data. The individual work history and exposure levels, both known and extrapolated, were used to calculate a retrospective exposure to dust for each individual operative. This was done blind to the identity and symptom status of each individual included in the study.

\section{ANALYSIS OF DATA}

Descriptive statistics are presented as means and confidence intervals for continuous variables. Proportions and $\chi^{2}$ tests were used for comparison of absolute value variables.

To analyse the effect of exposure to cotton on the prevalence of bronchitis, logistic regression analysis using SPSS software with chronic bronchitis as the dependent variable was performed. The effect of the current exposure to cotton was determined in a regression model with cumulative dust and cumulative smoking history (pack years) entered after the forced entry of the confounding factors of age, sex, and ethnic origin.

The effects of the symptomatic state on lung function was determined by two separate case control studies in which controls were matched for age, sex, ethnic origin, and current smoking habit with cases. Percentage predicted lung function values are presented as the mean with $95 \%$ confidence intervals. Because of differences in cumulative dust and cumulative smoking between the cases and controls, a conditional regression analysis was performed on the cotton control population to determine whether the effect of lung function by diagnosis was independent of past dust and smoke exposure, in addition to the matching criteria.

\section{Results}

A total of 2991 operatives were seen on at least one occasion during the first three years of the longitudinal study, of whom 2168 were employed in cotton mills (cases) and 823 were currently working in man-made fibre mills (controls). The response rate for participation has remained in excess of $90 \%$ throughout the three years of the study from which these data are drawn.

The demographic features of the two populations are given in table 1 . Overall, 190 workers gave a history compatible with the diagnosis of chronic bronchitis. Symptoms were more common in the cotton workers with a prevalence of $7.15 \%$ compared with $4.25 \%$ in
Table 1 Demographic features of the study populations

\begin{tabular}{|c|c|c|}
\hline Population & $\begin{array}{l}\text { Cotton } \\
(n=2168)\end{array}$ & $\begin{array}{l}\text { Man-made fibre } \\
(n=823)\end{array}$ \\
\hline Men (\%) & 75.0 & $61.5^{* *}$ \\
\hline $\begin{array}{l}\text { Caucasian (\%) } \\
\text { Asian (\%) } \\
\text { Other ethnic (\%) }\end{array}$ & $\begin{array}{r}69.1 \\
29.2 \\
1.7\end{array}$ & $\left.\begin{array}{r}68.0 \\
31.0 \\
1.0\end{array}\right\} \mathrm{NS}$ \\
\hline $\begin{array}{l}\text { Current smoker (\%) } \\
\text { Ex-smoker (\%) } \\
\text { Never smoked (\%) }\end{array}$ & $\begin{array}{l}51.2 \\
14.6 \\
34.2\end{array}$ & $\left.\begin{array}{l}48.1 \\
11.2 \\
40.7\end{array}\right\} * *$ \\
\hline Mean (SD) age (years) & $38.8(13.4)$ & $37.0(11.7)^{*}$ \\
\hline
\end{tabular}

$* * \mathrm{p}<0.001 ; * \mathrm{p}<0.05$.

Table 2 Distribution of bronchitis prevalence by confounders

\begin{tabular}{lll}
\hline Population & Cotton (\%) & $\begin{array}{l}\text { Man-made fibre } \\
(\%)\end{array}$ \\
\hline Male & 7.22 & 3.56 \\
Female & 6.63 & 5.36 \\
Caucasian & 8.13 & 5.36 \\
Asian & $3.95^{* *}$ & $1.96 \dagger$ \\
Current smokers & 9.21 & 7.32 \\
Ex-smokers & 6.98 & 3.26 \\
Never smoked & $3.91^{* * *}$ & $0.90^{* *}$ \\
Age & & \\
$\quad<25$ & 2.60 & 2.55 \\
$25-34$ & 5.01 & 5.35 \\
35-44 & 6.07 & 4.04 \\
$\quad 45-54$ & 10.00 & 4.79 \\
$\geq 55$ & $14.24^{* * *}$ & 3.45 \\
\hline
\end{tabular}

*** $\mathrm{p}<0.0001 ; * * \mathrm{p}<0.001 ; * \mathrm{p}<0.01 ; \dagger \mathrm{p}<0.05$.

those working in the man-made fibre mills $(\mathrm{p}<0.01)$.

Table 2 shows the distribution of the prevalence of chronic bronchitis within the population subgroups. The effect of age was analysed by dividing the cohort into decades $(<25$ years, 25-34 years, 35-44 years, 45-54 years, and $55+$ years). The prevalence of chronic bronchitis increased with age in cotton workers but this pattern was not seen in the man-made fibre workers. The slight excess of chronic bronchitis in men compared with women did not reach statistical significance in either the cotton or man-made fibre workers. Smoking was clearly significant with an increased prevalence of chronic bronchitis in current smokers compared with ex-smokers, and never smokers having the lowest prevalence. The overall prevalence of chronic bronchitis in man-made fibre workers who had never smoked was less than $1 \%$. Symptoms of chronic bronchitis were more common in white Caucasian subjects than in Asians. This is a feature of all symptoms included in the study and it is not known whether this represents a true ethnic difference, a problem with interpretation of the questionnaire, or a difference in working habits, social habits, or exposure effects.

Tables 3 and 4 present the regression analysis for the whole study population (including current cotton and man-made fibre workers). The effect of current exposure to cotton dust (table 3 ) and cumulative dust exposure (table 4) is analysed after the forced entry of sex, age, ethnic origin and pack years as potential confounding factors. No other variable relating to work history, dust or endotoxin exposure was identified as having a predictive effect in addition to those documented in the tables. 
Table 3 Predictive effect of exposure to cotton dust on chronic bronchitis after controlling for confounders and other predictive variables

\begin{tabular}{lccc}
\hline Factor & $\beta$ coefficient & Odds ratio $(95 \%$ CI) & $p$ value \\
\hline Age & -0.027 & $0.97(0.96$ to 0.98$)$ & $<0.0001$ \\
Ethnic group & 0.428 & $1.53(1.09$ to 2.16$)$ & $<0.05$ \\
Sex & 0.120 & $1.13(0.79$ to 1.61$)$ & NS \\
Pack years (10) & -0.237 & $0.79(0.71$ to 0.87$)$ & $<0.0001$ \\
Current cotton & 0.430 & $1.54(1.04$ to 2.28$)$ & $<0.05$ \\
\hline
\end{tabular}

Pack years $(10)=$ odds ratio and confidence intervals for a decrease of 10 pack years.

Table 4 Predictive factors for chronic bronchitis by logistic regression using lifetime measures of exposure to cotton dust

\begin{tabular}{lccc}
\hline Factor & $\beta$ coefficient & Odds ratio $(95 \%$ CI) & $p$ value \\
\hline Age & -0.0135 & $0.99(0.97$ to 1.00$)$ & $\mathrm{NS}$ \\
Ethnic group & 0.432 & $1.54(1.09$ to 2.17$)$ & $<0.05$ \\
Sex & 0.129 & $1.14(0.80$ to 1.62$)$ & $\mathrm{NS}$ \\
Pack years (10) & -0.234 & $0.79(0.71$ to 0.87$)$ & $<0.0001$ \\
Cumulative dust & -0.324 & $0.72(0.59$ to 0.88$)$ & $<0.0005$ \\
\hline
\end{tabular}

Confidence intervals for pack years and cumulative dust represent values related to a decrease of 10 pack years and $10 \mathrm{mg}$ years $/ \mathrm{m}^{3}$, respectively.

Table 5 Predictive effect of exposure to cotton dust on chronic bronchitis after controlling for confounders and other predictive variables in a subpopulation aged over 45 years $(n=$ 1046)

\begin{tabular}{lclc}
\hline Factor & $\beta$ coefficient & Odds ratio $(95 \%$ CI) & $p$ value \\
\hline Age & -0.025 & $0.97(0.94$ to 1.02$)$ & NS \\
Ethnic group & 0.438 & $1.55(0.98$ to 2.44$)$ & NS \\
Sex & 0.068 & $1.07(0.66$ to 1.73$)$ & NS \\
Pack years (10) & -0.172 & $0.84(0.75$ to 0.94$)$ & $<0.005$ \\
Current cotton & 0.922 & $2.51(1.29$ to 4.89$)$ & $<0.01$ \\
\hline
\end{tabular}

Pack years $(10)=$ odds ratio and confidence intervals for a decrease of 10 pack years.

Table 6 Uncorrected odds ratio for developing bronchitis in white Caucasian men and women over the age of 45 by occupational exposure type and smoking habit

\begin{tabular}{llll}
\hline & Smoker & Ex-smoker & Never smoked \\
\hline Cotton & 9.3 & 8.0 & 5.3 \\
Man-made fibre & 4.9 & 3.0 & 1 \\
\hline
\end{tabular}

Table 5 presents the same analysis when only workers over the age of 45 were included to assess the effect of current exposure to cotton in this high risk subpopulation. Table 6 presents the unadjusted odds ratios for chronic bronchitis in the highest risk group only - that is, white Caucasians over the age of 45 years (thus eliminating the confounding effect of ethnic origin and minimising any effect of age). The

Table 7 Demographic features, dust exposures, pack years, and percentage predicted lung function of cases and controls in the intra-cotton case referent study

\begin{tabular}{lll}
\hline & $\begin{array}{l}\text { Bronchitics } \\
(n=153)\end{array}$ & $\begin{array}{l}\text { Controls } \\
(n=306)\end{array}$ \\
\hline Male (\%) & 77 & 77 \\
Mean (SD) age (years) & $45.9(11.3)$ & $45.9(12.2)$ \\
Caucasian (\%) & 81 & 81 \\
Asian (\%) & 17 & 17 \\
Other ethnic (\%) & 2 & 2 \\
Current smoker (\%) & 66.0 & 66.0 \\
Ex-smoker (\%) & 14.4 & 14.4 \\
Never smoked (\%) & 19.6 & 19.6 \\
Pack years (95\% CI) & $17.7(15.0$ to 20.4$)$ & $15.5(13.8$ to 17.2$)$ \\
Dust exposure (mg/m $\left.{ }^{3}\right)$ & & \\
$\quad$ Work area dust & $0.74(0.65$ to 0.82$)$ & $0.81(0.74$ to 0.88$)$ \\
$\quad$ Personal dust & $3.68(2.03$ to 5.33$)$ & $2.38(2.05$ to 2.71$) \dagger$ \\
$\quad$ Cumulative dust & $15.7(14.0$ to 17.4$)$ & $13.8(12.7$ to 15.0$) \dagger$ \\
\% Predicted lung function & & \\
$\quad$ FEV & & $86.7(84.9 \text { to } 88.5)^{*}$ \\
$\quad$ FVC & $81.4(78.3$ to 84.6$)$ & $94.6(92.8 \text { to } 96.4)^{*}$ \\
\hline
\end{tabular}

$\mathrm{FEV}_{1}=$ forced expiratory volume in one second; $\mathrm{FVC}=$ forced vital capacity.

$* \mathrm{p}<0.01 ;+\mathrm{p}<0.05$. odds reported are compared with the prevalence of chronic bronchitis in all white Caucasian workers over the age of 45 who are not current smokers $(2.0 \%)$.

\section{CASE REFERENT STUDY}

Absolute matching for each case of chronic bronchitis was achieved with two controls currently exposed to cotton with regard to sex, ethnic origin, current smoking status, and age (within three years). This was achieved for 153 of the 155 cases. One individual could not be matched because he was still working at the age of 74 and a second could not be matched because she was the only smoking Asian female among the cotton workers. These cases were therefore eliminated from this stage of the analysis.

The second case referent analysis was performed with each case of bronchitis matched to one referent within the control population matched on the same criteria, with the exception of age for which \pm 5 years was used to allow for the smaller number in the control population. A further five individuals were impossible to match because of the small number of older man-made fibre workers, leaving a matched group of 148 cases and 148 controls in this case control analysis.

Predicted forced expiratory volume in one second $\left(\mathrm{FEV}_{1}\right)$ values for cases and controls were identical in both case control studies (3.19 litres). Tables 7 and 8 present the demographic features, pack years, mean current and cumulative dust exposures (table 7 only; cotton exposed workers), and mean lung function parameters of cases and controls within the two case referent analyses.

The conditional regression analysis, performed on the intra-cotton case referent population, was performed to account for the additional confounding effects of pack years and cumulative dust exposure. A study diagnosis of bronchitis remained significant in predicting both a reduction in $\mathrm{FEV}_{1}(\mathrm{R}=0.286$; $\mathrm{df}=445 ; \mathrm{p}<0.01)$ and FVC $(\mathrm{R}=0.219 ; \mathrm{df}=$ $445 ; \mathrm{p}<0.05)$.

\section{Discussion}

The design of the analysis has allowed a comparison of the prevalence of chronic bronchitis between cotton workers and those working with man-made fibre textiles. The latter group do not form a perfect control group as there is some limited dust exposure in all the jobs in man-made fibre textile mills. There is also increasing evidence that working with manmade fibre can cause an increased loss of lung function ${ }^{11}$ and the results of the longitudinal study from which these data are drawn ${ }^{7}$ also suggest a reduction in forced vital capacity in a cross sectional analysis of man-made fibre workers. The asymptomatic controls in the man-made fibre population within the current analysis also had a small loss of lung function compared with predicted values. In addition, many of the man-made fibre workers had been exposed to cotton dust in the past, which may 
Table 8 Demographic features, dust exposures, pack years, and percentage predicted lung function of cases and controls in the cotton bronchitic:man-made fibre control case referent study

\begin{tabular}{lll}
\hline & $\begin{array}{l}\text { Bronchitics } \\
(n=148)\end{array}$ & $\begin{array}{l}\text { Controls } \\
(n=148)\end{array}$ \\
\hline Male (\%) & 75.7 & 75.7 \\
Mean (SD) age (years) & $45.1(12.0)$ & $45.1(11.6)$ \\
Caucasian (\%) & 80.4 & 80.4 \\
Asian (\%) & 18.2 & 18.2 \\
Other ethnic (\%) & 1.4 & 1.4 \\
Current smoker (\%) & 65.5 & 65.5 \\
Ex-smoker (\%) & 14.9 & 14.9 \\
Never smoked (\%) & 19.6 & 19.6 \\
Pack years (95\% CI) & $16.9(14.4$ to 19.4$)$ & $16.3(13.8$ to 19.0$)$ \\
\% Predicted lung function & & \\
$\quad$ FEV & $81.5(78.3$ to 84.7$)$ & $84.7(82.1$ to 87.3$) \dagger$ \\
FVC & $90.0(87.0$ to 93.0$)$ & $91.5(89.0$ to 94.0$)$ \\
\hline
\end{tabular}

$\mathrm{FEV}_{1}=$ forced expiratory volume in one second; $\mathrm{FVC}=$ forced vital capacity.

$+\mathrm{p}<0.05$. lations. The fact that male smokers of lower social class have a higher prevalence of chronic bronchitis is well reported, and smoking remains the most important factor in determining chronic bronchitis.

Studies have repeatedly shown that Asians are less likely to report symptoms than Caucasians $^{7}$ and their presence in such studies will be an additional confounder. Our study has attempted to account for the above factors and, while accepting the limitations of a cross sectional approach and the control population used, the study provides convincing evidence of an excess of chronic bronchitis in cotton exposed workers. The size of the study population has allowed sufficient never smoking workers to be included to control adequately for the effect of smoking before determining the effect of dust exposure. The study has shown that smoking and exposure to cotton dust act additively in increasing the risk of chronic bronchitis.

After accounting for life long exposure to dust and smoking, current estimates of exposure - whether to cigarettes or measures of personal dust, work area dust or airborne endotoxins - add nothing to the regression model for chronic bronchitis. The chronic nature of the disease and associated fixed airways obstruction with which it is clinically and physiologically associated makes these findings unsurprising.

In the crude analysis of high risk workers within the white Caucasian population over the age of 45 , the risk of chronic bronchitis was as high in never smoking cotton workers as in lifelong smoking man-made fibre workers (both approximately five times the risk of never smoking man-made fibre textile workers). In the whole population, including individuals of all ages and ethnic origin, current exposure to cotton dust was associated with an odds ratio of approximately 1.5 (confidence intervals 1.1 to 2.3) for developing chronic bronchitis after accounting for confounding factors and pack years of smoking.

The use of an additional case referent design analysis of cases of chronic bronchitis, matched for age, sex, ethnic group, and smoking habit with workers without chronic bronchitis, had the advantage of eliminating the effects of personal confounders and predicted lung function equations (there is particular concern with regard to the accuracy of predictor values for Asians in this population ${ }^{7}$ ).

The results show that the symptomatic "bronchitic" state was associated with a reduction in measured lung function. The extent of the additional loss is small compared with the reduction that is present even in asymptomatic workers when compared with predicted values. Bronchitic workers were found, on average, to have a crude value of $200 \mathrm{ml}$ total loss of FEV compared with their matched asymptomatic controls. If this reduction only occurred after developing the symptoms, using the subjective assessment of individuals of the duration of their symptoms (mean 9.2 years), an excess decline of approximately $20 \mathrm{ml} /$ year is estimated. In reality these individuals probably 
represent the susceptible pool and may have had an excess decline before developing symptoms and, if the denominator of the time spent in the industry is used to calculate the excess decline (22 years), the value in these workers is only approximately $8 \mathrm{ml} /$ year. Although these estimates are crude, a symptomatic worker may be expected to lose $\mathrm{FEV}_{1}$ at a rate between 8 and $20 \mathrm{ml} /$ year more than the asymptomatic worker. This will be further elucidated by the longitudinal study. Matching to current smoking habit and current cotton dust exposure did not completely eradicate the effect of cumulative smoking habits or cumulative dust exposure. The conditional regression analysis, however, confirms that individuals with chronic bronchitis as diagnosed in this study have a lower lung function than controls matched for age, sex, current smoking status, and ethnic group after allowing for pack years of smoking and cumulative dust exposures.

The second case referent study matched bronchitic cotton workers with a single nonbronchitic man-made fibre textile worker. The man-made fibre controls had lower lung function values than the cotton controls. This is most noticeable for FVC $(94.6 \%$ in cotton workers; $91.5 \%$ in man-made fibre workers). "Bronchitic" workers exposed to cotton also had lower $\mathrm{FEV}_{1}$ values than their man-made fibre controls but the difference was reduced, while there was no significant reduction in FVC. This latter finding would seem, in the light of other published data, to support a decline in FVC in workers exposed to manmade fibre.

In conclusion, this cross sectional analysis of a large population of textile workers has allowed the determination of the effect of exposure to cotton on the prevalence of chronic bronchitis compared with a control group of man-made fibre textile workers. Chronic bronchitis is more common in cotton workers and, once the confounding effects of age, sex, ethnic group and smoking habits of the study population have been accounted for, cumulative exposure to dust was the only factor that was found to be predictive of the development of chronic bronchitis. This bronchitic state is associated with a loss of lung function compared with the non-symptomatic state, but the difference is small.

1 Committee on Research into Chronic Bronchitis. Questionnaire in respiratory symptoms: instructions for its use. London: Medical Research Council, 1966.

2 Marine WM, Gurr D, Jacobsen M. Clinically important respiratory effects of dust exposure and smoking in British coal miners. Am Rev Respir Dis 1988;137:106-12.

3 Karava R, Hernberg S, Koskela RS, Luoma K. Prevalence of pneumoconiosis and chronic bronchitis in foundry workers. Scand $\mathcal{F}$ Work Environ Health 1976;2:64-72.

4 Hunting KL, Welch LS. Occupational exposure to dust and lung disease among sheet metal workers. $\mathrm{Br} \mathcal{F}$ Ind Med lung disease among

5 American Thoracic Society, statement. Snowbird workshop on standardisation of spirometry. Am Rev Respir Dis 1979; 119:831-8.

6 Quanjer P, ed. Standardised lung function testing. Report of Working Party on Standardisation of Lung Function Tests. Bull Eur Physiopathol Respir 1983;19(Suppl 5):4551 .

7 Fishwick D, Fletcher AM, Pickering CAC, Niven RMcL, Faragher EB. Lung function, bronchial reactivity, atopic status and dust exposure in Lancashire cotton mill operatives. Am Rev Respir Dis 1992;145:1103-8.

8 Health and Safety Executive. Guidance note EH25, cotton dust sampling. London: HMSO, 1980.

9 Gould M, Olenchock S. Endotoxin extraction method fo organic dusts. In: Rylander R, Burrell R, Peterson Y, eds. Proceedings of endotoxin inhalation workshop. 1987:204-5.

10 Niven RMcL, Fishwick D, Pickering CAC, Fletcher AM, Warburton CJ, Crank P. A study of the performance and comparability of the dust sampling response to cotton dust of work area and personal sampling techniques. $A n n$ Occup Hyg 1992;36:349-62.

11 Glindmeyer HW, Lefante JJ, Jones RN, Rando RJ, Abdelkader HM, Weill $\mathrm{H}$. Exposure related decline in the lung function of cotton textile workers. Am Rev Respir Dis 1991;144:675-83.

12 Berry G, Molyneux MKB, Tombleson JBL. Relationship between dust level and byssinosis and bronchitis in Lancashire cotton mills. Br f Ind Med 1974;31:18-27.

13 Fletcher AM, Fishwick D, Pickering CAC, Niven RMcL A two year study of respiratory symptoms in cotton and man-made fibre workers. In: Proceedings of the 15th Beltwide cotton dust research conference, National Cotton Council cotton dust research conference,

14 Love RG, Smith TA, Gurr D, Soutar CA, Scarisbrick DA, Seaton A. Respiratory and allergic symptoms in woo textile workers. Br f Ind Med 1988;45:727-41. 